DELGADO, Jordi. "Problemas y tensiones entre el diseño y funcionamiento del procedimiento monitorio penal".

Polít. crim. Vol. 10, № 19 (Julio 2015), Art. 1, pp. 1-24.

[http://www.politicacriminal.cl/Vol_10/n_19/Vol10N19A1.pdf]

\title{
Problemas y tensiones entre el diseño y funcionamiento del procedimiento monitorio penal $^{*}$
}

\section{Problems and tensions between the design and the operation of the criminal admonition procedure}

\author{
Jordi Delgado Castro \\ Doctor en Derecho, Profesor de Derecho Procesal, Universidad de Talca \\ jdelgado@utalca.cl
}

\section{Resumen}

El siguiente estudio pretende ayudar a la conceptualización del procedimiento monitorio penal como medio de encontrar las características que le son propias. A su vez, destacar los principales elementos que, sin duda, han de replicarse en los monitorios de los procedimientos reformados $\mathrm{y}$, en último lugar, señalar algunos problemas prácticos que han acontecido en la práctica forense. Aspira, entonces, ser un aporte a futuras investigaciones sobre monitorio, así como contribuir a destacar algunos nudos críticos actuales.

Palabras clave: Procedimiento Monitorio Penal, Procedimiento Monitorio en Chile, Reformas Procesales en Chile.

\begin{abstract}
The purpose of this paper is to describe the criminal admonition procedure and list its main features. Moreover, this paper lists some key points that need to be replicated in the upcoming updates of legal procedures. Finally, it highlights some practical issues arising from forensic practices. The paper thus aspires to contribute to the ongoing research on admonitory procedures as well as to help highlight current critical issues.
\end{abstract}

Key words: Criminal admonition procedure, Admonition Procedure in Chile, Procedural Reforms in Chile.

\section{Introducción.}

El procedimiento monitorio llegó a Chile de la mano de la Reforma Procesal Penal. Es un tipo procedimental de alta importancia debido al impacto estadístico que ha tenido en nuestro sistema de justicia $\mathrm{y}$, por otra parte, a la incorporación de un procedimiento desconocido de frecuente uso y éxito en nuestro entorno jurídico cultural.

* Este trabajo corresponde a parte de los resultados del Proyecto financiado por el Fondo Nacional de Desarrollo Científico y Tecnológico, FONDECYT Iniciación № 11130664: "Problemas de diseño del procedimiento monitorio civil chileno. Una evaluación desde las experiencias del Derecho comparado". 
DELGADO, Jordi. "Problemas y tensiones entre el diseño y funcionamiento del procedimiento monitorio penal".

La presente investigación parte de la necesidad de realizar un estudio acabado sobre el concepto y los principales aspectos problemáticos que permitan determinar tensiones e inconsistencias en el diseño del procedimiento monitorio que, sin duda, pueden servir para anticipar problemas en futuras legislaciones. ${ }^{1}$

De este modo, sostendremos como principal hipótesis que la llegada del procedimiento monitorio determina la conformación de un cambio en el paradigma del enjuiciamiento que, en cierto modo, choca con los principios que inspiran todos los procedimientos reformados y que en su diseño específico presenta diversas falencias.

Adicionalmente, significarán los objetivos de este trabajo la tarea de arrojar luces acerca de los elementos que conforman a un monitorio como tal, en atención a las experiencias cercanas en el derecho comparado y, en específico, observar qué se ha entendido por procedimiento monitorio penal y cuáles son sus principales notas definitorias.

De este modo, se propone un avance en el conocimiento que conduzca a que futuras investigaciones sobre monitorio laboral y monitorio civil cuenten con los elementos dogmáticos suficientes para avanzar en la definición de una técnica monitoria nacional y pueda prever eventuales aspectos problemáticos que merecen especial atención.

\section{1. ¿Qué es procedimiento monitorio?}

El procedimiento monitorio, en los términos más generales posibles, es un procedimiento breve, sencillo y concentrado ${ }^{2}$. Efectivamente, es un medio para la resolución del conflicto cuyo objetivo es obtener una respuesta rápida en aquellos casos en que las circunstancias que rodean a los hechos no ameritan, diáfanamente, la necesidad de una tramitación compleja que pueda observar al detalle las vicisitudes que envuelve la relación jurídica.

En otros términos es la eterna huida del solemnis ordo iudiciarius ${ }^{3}$. En numerosas de lecciones de historia del derecho procesal hemos aprendido que aquel proceso responde a las características de lento, complicado, formalista y caro ${ }^{4}$. Un proceso que se desarrolla mediante un procedimiento ordinario y plenario. De este modo, se conoce de la generalidad de los asuntos y no existe limitación alguna a las alegaciones, pruebas, ni medios de prueba que puedan presentar las partes, desplegándose así completamente los efectos de la cosa juzgada material ${ }^{5}$.

\footnotetext{
${ }^{1}$ Una interesante proyección hacia la Reforma Procesal Civil, PALOMO VÉLEZ, Diego, "Reformas de la ejecución civil y del proceso monitorio: La apuesta chilena por la tutela judicial efectiva y el derecho de acceso a un debido proceso", Estudios Constitucionales, Año 12, № 1 (2014), pp.475-500, p. 475.

${ }^{2}$ CORREA DELCASSO, Juan Pablo, El proceso monitorio, Barcelona: Editorial J. M. Bosch, 1998, p. 13.

${ }^{3}$ TOMÁS Y VALIENTE, Francisco, "Estudio históricojurídico del proceso monitorio", Revista de Derecho Procesal, $\mathrm{N}^{\mathrm{o}} 1$ (1960), pp. 31-132, p. 33.

${ }^{4}$ MONTERo AROCA, Juan, El Proceso Civil. Los Procesos Ordinarios de Declaración y de Ejecución, Valencia: Tirant lo Blanch, 2014, p. 554.

${ }^{5}$ MONTERO AROCA, El Proceso Civil, cit. nota ${ }^{\circ} 5$.
} 
Polít. crim. Vol. 10, № 19 (Julio 2015), Art. 1, pp. 1-24.

[http://www.politicacriminal.cl/Vol_10/n_19/Vol10N19A1.pdf]

Precisamente, estas características son la antítesis de las llamadas reformas procesales. Desde la primera gran reforma en nuestro país, Reforma Procesal Penal ${ }^{6}$, uno de los objetivos más importantes ha sido la búsqueda de la celeridad en la respuesta procesal, como forma de conseguir la eficacia en la resolución del conflicto.

Por lo tanto, antes de ahondar en otras consideraciones acerca del procedimiento monitorio, podríamos señalar que no es más que un mecanismo de simplificación del procedimiento usado en la función de adjudicación cuyo objetivo es entregar una respuesta rápida a las partes.

Aproximándonos al concepto, con un sentido matiz civil como se desprende de su origen, podríamos señalar que el procedimiento monitorio es un tertium genus entre la cognición y la ejecución forzada por el que ante la solicitud de una parte el juez emite una providencia que sirve de título ejecutivo, salvo que aquel contra quien se promueve se oponga a ello ${ }^{7}$.

\section{El procedimiento monitorio penal: un boceto histórico comparado.}

Habitualmente, las investigaciones sobre monitorio se concentran en el monitorio civil ${ }^{8}$. Las reformas procesales chilenas postergaron la renovación de la norma rituaria civil y se configuró con anterioridad en los procesos penal y laboral. El monitorio penal tiene una serie de notas características que lo definen como monitorio y una aproximación desde el derecho histórico comparado nos permitirá delimitar aspectos esenciales de nuestro monitorio penal.

\footnotetext{
${ }^{6}$ El propio Mensaje que antecede al Código Procesal Penal señala claramente: "el desarrollo económico ha supuesto y supondrá en el futuro un creciente número y variedad de los litigios, que exigen, a la vez, rapidez. y eficiencia en su resolución"; "se propone la creación de de algunos procedimientos simplificados en que por la vía de acuerdos entre todos los intervinientes o de algunos de ellos, se supriman etapas del curso ordinario del procedimiento de modo que se permita alcanzar una solución rápida del caso por medio de una sentencia definitiva" (Historia de la Ley $\mathrm{N}^{\circ}$ 19.696, pp. 5 y 327).

${ }^{7}$ CARNELUTTI, Francesco, Instituciones del Proceso Civil, Trad. SENTÍS MELENDO, Santiago, Buenos Aires: Ediciones Jurídicas Europa-America, 1973, pp. 83 a 85. Es difícil encontrar una definición completa de procedimiento monitorio, tal y como señala CORREA DELCASSO, El proceso monitorio, cit. nota $\mathrm{n}^{\mathrm{o}} 2$, $\mathrm{p}$. 211: "proceso especial plenario rápido, que tiende, mediante la inversión de la iniciativa del contradictorio, a la rápida creación de un título ejecutivo con efectos de cosa juzgada en aquellos casos que determina la ley" (citando a CRISTOFOLINI, Giovanni, Processo d'ingiunzione, Padova: Ed. Cedam, 1939, p. 30; Actualmente, la definición doctrinal de la institución no ha variado sustancialmente: "el proceso monitorio tiende a la rápida creación del título ejecutivo que se produce ante el silencio del deudor. Si éste se opone, concluye el proceso monitorio pues se ha frustrado su razón de ser, debiéndose iniciar un proceso ordinario para discutir la certeza de lo reclamado inicialmente" (PICÓ I JUNOY, Joan, "Nuevas perspectivas sobre la debida armonización del proceso monitorio y el posterior juicio ordinario", Justicia: Revista de Derecho Procesal, № 1 (2013), pp. 41-106, p. 49).

${ }^{8}$ Además, del monitorio civil irradia su sustratum, en palabras de RAMOS GONZÁLEZ, José María, “Repercusiones penales del proceso monitorio", Poder Judicial, No 699 (1966), pp. 3-5, p. 4.
} 
DELGADO, Jordi. "Problemas y tensiones entre el diseño y funcionamiento del procedimiento monitorio penal".

La doctrina es pacífica en arrogar el origen del procedimiento monitorio en la Italia ${ }^{9}$ Altomedieval motivado por la creciente actividad mercantil que demandaba de nuevos instrumentos ${ }^{10}$. De este modo, podemos afirmar que, en primer lugar, un procedimiento monitorio es un procedimiento especial ${ }^{11}$. En aquella huida del formalismo y la lentitud se diseña un procedimiento que haciendo uso de la técnica monitoria ${ }^{12}$ sirva como instrumento de entrega de una decisión rápida y, por este motivo, una de sus principales características es la conformación específica de su articulado pensando en una consecución inmediata de su objetivo ${ }^{13}$.

En esa misma lógica de la búsqueda de la rapidez, el procedimiento monitorio, en su faceta penal, es un medio de enjuiciamiento rápido ${ }^{14}$. Ahora bien, la primera pregunta que nos pudiera plantear esta afirmación es si un enjuiciamiento rápido $-\mathrm{o}$ su ausencia propiamente $\mathrm{tal}^{15}$ - se corresponden con los principios de nuestro proceso penal ${ }^{16}$.

${ }^{9}$ Uno de los estudios referentes en el campo y voz más autorizada, así lo propone: CALAMANDREI, Piero, El proceso monitorio, Trad. SENTÍS MELENDO, Santiago, Buenos Aires: Bibliográfica Argentina, 1946, p. 26.

${ }^{10}$ En este sentido, TOMÁS Y VALIENTE, "Estudio históricojurídico", cit. nota no 3, p. 33 y ss. Es pertinente, sin embargo, señalar que no siempre se ha tratado de una discusión pacífica. Existen, como demuestra Nieva Fenoll (NIEVA FENOLL, Jordi, “Aproximación al origen del procedimiento monitorio", en: NIEVA FENOLL, Jordi; RIVERA MORALES, Rodrigo; COLMENARES URIBE, Carlos y CORREA DELCASSO, Juan Pablo, El procedimiento monitorio en América Latina, Bogotá: Temis, 2013, p. 1 y ss.) otras hipótesis que apuestan por un origen germánico pese a estar sobradamente desacreditadas (SKEDL, Arthur, Das Mahnverfahren, Leipzig, 1891, p. 1 a 15).

${ }^{11}$ Es lo que Fairén (FAIRÉN GUILLEN, Victor, El juicio ordinario y los plenarios rápidos, Barcelona: Bosch, 1953, p.42) llamó la sumarización del proceso común.

${ }^{12}$ Fue Lorca Navarrete quien acuñó esta expresión. De este modo se usa la técnica monitoria "cuando los hechos aparecen claramente establecidos y parece cierto que el denunciado es el autor de la infracción" (LORCA NAVARRETE, Antonio María, El procedimiento monitorio civil, San Sebastián: Instituto Vasco de Derecho Procesal, 1988, p. 17).

${ }^{13}$ Especialmente acertado parece en este sentido el estudio de Gutiérrez-Alviz y Conradi (GUTIÉRREZALVIZ y CONRADI, Faustino, El procedimiento monitorio. Estudio de Derecho comparado, Sevilla: Anales de la Universidad Hispalense, 1978, p. 17 y 18) "ésta era la especialidad del proceso monitorio, lo que evidentemente suponía una notoria innovación por su sencillez, abreviación y simple tramitación en relación al formalista ritual y complejo juicio ordinario, frente al cual y como reacción necesaria surgía en la vida y práctica jurídica".

${ }^{14}$ Sin duda, resulta muy gráfica esa fijación por la economía procesal que puede verse en toda la Historia de la Ley. Respecto a este particular, por ejemplo: "Así, creó el llamado "procedimiento monitorio", para el caso de una falta sancionable sólo con pena de multa. Se desea ahorrar personal, papel, tiempo, etcétera". Historia de la Ley $\mathrm{N}^{\mathrm{o}}$ 19.696, p. 1611.

${ }^{15}$ CALAMANDREI, El proceso monitorio, cit. nota $\mathrm{n}^{\circ}$ 9, p. 132: "que los hechos afirmados por el demandante valen como verdaderos sin necesidad de prueba, en cuanto el deudor no niegue su verdad mediante la oposición a la inyunción". Observamos, entonces, que no existe más que una aplicación casi automática de la subsunción de la norma, en tanto, los hechos se presumen verdaderos.

${ }^{16}$ En una primera y poco concienzuda mirada podríamos pensar que se atenta al principio del Derecho al juicio previo y los subprincipios que implica como el proceso previo legalmente tramitado, el derecho a la defensa, el derecho a la presunción de inocencia, la carga probatoria que recae en el órgano estatal, o el derecho a ser tratado como inocente (Para una correcta comprensión puede consultarse, LÓPEZ MASLE, Julián, "Principios y Garantías del sistema procesal penal chileno", en: HORVITZ LENNON, María Inés; LÓPEZ MASLE, Julián, Derecho Procesal Penal chileno, t. I, Santiago: Editorial Jurídica de Chile, 2008, pp. 62 y ss; DELMAS-MARTY, Mireille, Procesos Penales en Europa. Alemania, Inglaterra y Gales, Bélgica, 
Polít. crim. Vol. 10, № 19 (Julio 2015), Art. 1, pp. 1-24.

[http://www.politicacriminal.cl/Vol_10/n_19/Vol10N19A1.pdf]

Efectivamente, a diferencia de los sistemas anglosajones en que la confesión ${ }^{17}$ es suficiente para declarar culpable al acusado, nuestro sistema proscribe dicha posibilidad ${ }^{18}$. Sin embargo, es indudable que en algún modo existe una influencia derivada de la figura de la plea bargaining ${ }^{19}$. En relación con esta misma idea, el monitorio penal parte desde la condena (sin audiencia al imputado ${ }^{20}$ y permite la oposición a la misma; más que una defensa propiamente tal que, en su caso, deberá ejercer con posterioridad. Es necesario señalar que en nuestro sistema no se le entrega la oportunidad formal de pronunciarse acerca de su culpabilidad o inocencia, sino más bien, se extraen las consecuencias derivadas de su actitud.

Así ha sido, también, desde su conformación originaria y quizá por eso la doctrina decimonónica señaló su origen en aquella figura inglesa ${ }^{21}$.

Pudiera afirmarse que el procedimiento monitorio penal tiene su antecedente histórico más paradigmático en el Código de Procedimiento Penal italiano de $1913^{22}$ que contempla un pronunciamiento llamado Procedimento per Decreto ${ }^{23}$ cuyo principio rector es el de arbitrio y no el de legalidad ${ }^{24}$. Apareciendo, también en el origen histórico ${ }^{25}$ un viso de ausencia de lo que hoy entendemos por debido proceso en el ámbito penal ${ }^{26}$.

Francia e Italia, Trad. MORENILLA ALARD, Zaragoza: Ed. EDIJUS, 2000, pp. 661 a 695: Demuestra que existe una tendencia hacia la privatización del proceso penal en los asuntos conocidos como criminalidad de bagatela desde la influencia penal que se ha producido desde los años setenta en la llamada justicia consensuada o justicia contratada.

${ }^{17}$ CERDA SAN MARTÍN, Rodrigo, Elementos fundamentales de la actividad probatoria, Santiago: Librotecnia, 2010, p. 67: "los hechos reconocidos no pertenecen al juzgamiento fáctico sino que pasan directamente al juzgamiento jurídico".

${ }^{18}$ ZAPATA GARCÍA, María Francisca, "La confesión en el nuevo sistema procesal penal: ¿Una reina que perdió su trono?", Gaceta Jurídica, № 252 (2001), pp. 18-19, p. 19: "el nuevo sistema procesal penal ha introducido un cuadro normativo tendiente a reforzar la idea de entender la declaración del imputado como un medio de defensa, sin que ello signifique excluir la confesión como un medio para producir fe. Es decir, esta reina, si bien ha perdido su trono, sigue gozando de buena salud".

${ }^{19}$ Efectivamente, como señala MARTÍN DELPONT, José Luis, El principio de oportunidad: Análisis de Derecho Comparado, Sevilla: Anales de la Facultad de Derecho, No 28, 2011, pp. 194 a 196, en el sistema norteamericano una vez el acusado conoce formalmente el contenido de los delitos que se le imputan, el acusador puede realizar una oferta de acuerdo. El imputado puede negarse a declarar (plea of nolo contendere), puede declararse no culpable (plea of not guilty), o puede declararse culpable (plea of guilty). Este último caso, conduce directamente a la sentencia condenatoria, siempre que el tribunal autorice el acuerdo.

${ }^{20} \mathrm{Si}$ bien es cierto que resulta muy complejo sostener en la práctica que el imputado goza en los demás procedimientos de una presunción de inocencia que lo protege. Para una mejor comprensión, LAUDAN, Larry, Verdad, error y proceso penal, Trad. VÁZQUEZ, Carmen; AGUILERA, Edgar, Madrid: Marcial Pons, 2013, p.142.

${ }^{21}$ Por todos, LONGHI, Silvio, Il Decreto Penale e le sue transformazioni, Milán: Scuola Positiva, 1911, p. 337.

${ }^{22}$ Un interesante análisis sobre este proyecto en CORDERO, Franco, Procedura penale, Milán: Giuffrè, 2006.

${ }^{23}$ BELLAVISTA, Girolamo, Il procedimento penale monitorio, Milán: Giuffrè, 1952, p. 6.

${ }^{24}$ En efecto, muy ciertamente lo describe SPANGHER, Giorgio, Procedimenti speciali, guidizio, procedimento davanti al tribunale e in composizione monorgratica, Milán: Wolters Kluwer Italia, 2008, p. 436: "Según algunos procesalistas e historiadores del derecho, en su realidad histórica el procedimiento 
DELGADO, Jordi. "Problemas y tensiones entre el diseño y funcionamiento del procedimiento monitorio penal".

Sin perjuicio del antecedente más moderno, la doctrina también ha señalado precedentes en la monición eclesiástica ${ }^{27}$. Así, Inocencio III consagra un tipo de procedimiento cuya característica principal pasa por requerir con anterioridad al pecador y solamente su actitud negativa determinaría la actuación del Derecho Canónico en su máximo esplendor ${ }^{28}$.

Este fenómeno procesal, en términos generales, comienza a expandirse después de la Primera Guerra Mundial en que la doctrina europea ${ }^{29}$ comienza a explorar nuevas formas de entregar una tutela penal más rápida, motivada por un contexto de crecimiento en las conductas criminales menos graves ${ }^{30}$.

Pareciera, desarrollarse y consolidarse al punto que una recomendación del Consejo de Europa del año $1987^{31}$ proponía una reconversión del sistema judicial y sus procedimientos apostando por una racionalización de los recursos que permitiera destinar la mayor cantidad de esfuerzo a la persecución penal de asuntos de mayor complejidad o gravedad ${ }^{32}$. En resumen se proponían tres focos: descriminalización y creación de procedimientos administrativos sancionatorios; potenciación del principio de oportunidad e instauración del procedimiento penal monitorio ${ }^{33}$.

monitorio aparece como una exasperación del proceso inquisitivo, derivado de su regreso al proceso sumario y de plano usado en el derecho medieval del siglo quince".

${ }^{25}$ Esta figura tendría, entonces, su origen moderno penal en el cuerpo normativo de mayor influjo italiano y huida de lo francés. En este sentido, FLORIAN, Eugene, Elementos de Derecho Procesal Penal, Trad. PRIETO CASTRO, México: Editorial Jurídica Universitaria, 2002, p. 12: "Este código, de confección tan laboriosa, ha sido sometido a multitud de críticas y censuras, pero, a nuestro juicio, tiene algunos méritos, que hay que reconocer objetivamente. Es una obra de factura eminentemente italiana y no ha experimentado más que levemente la influencia francesa".

${ }^{26}$ COLOMBO CAMPBELL, Juan, Los Actos Procesales, Santiago: Editorial Jurídica de Chile, 1997, p. 133.

27 DOMÍNGUEZ MARTÍN, Salvador, El procedimiento monitorio penal, Madrid: Instituto Nacional de Prospectiva, 1980 , p. 7.

${ }^{28} \mathrm{Si}$ bien es cierto que varios son los autores que reconocen fuentes canónicas al procedimiento monitorio, no lo es menos que desde el proceso extra ordinem romano ya se encuentran cogniciones sumarias como un modelo de proceder en base a un examen superficial o prima facie. Véase, GUTIÉRREZ-ALVIZ/ CONRADI, El procedimiento monitorio, cit. nota $\mathrm{n}^{\mathrm{o}} 13$, p. 18.

${ }^{29}$ Sin duda, existe en Europa una influencia norteamericana muy destacada, tal y como señala MIRA ROS, Corazón, Régimen actual de la conformidad, Madrid: Colex, 1998, p. 194.

${ }^{30}$ Véase, ARMENTA DEU, María Teresa, Criminalidad de bagatela y principio de oportunidad: Alemania y España, Barcelona: Ed. PPU, 1991, p. 23.

${ }^{31}$ Se trata de la Recommendation $\mathrm{N}^{\mathrm{o}} 18$ de 1987 referente a la simplificación de la justicia criminal. Los ejes literalmente eran: "recurrir al principio de oportunidad; uso de las siguientes medidas cuando se trate de delitos menores: los denominados procedimientos sumarios; arribo a acuerdos extrajudiciales por las autoridades competentes en materia penal y otras autoridades que intervienen, como una posible alternativa al enjuiciamiento; uso de los denominados procedimientos simplificados y la simplificación del procedimiento judicial ordinario".

${ }^{32}$ Debate, por otra parte, plenamente vigente hoy: CALAZA LÓPEZ, Sonia, “¿Podría instaurarse una Jurisdicción Voluntaria Penal?”, Revista de Derecho UNED, No 10 (2012), pp.69-89, p. 72.

${ }^{33}$ Recommendation $N^{\circ}$ 18, 1987: "La renuncia o la interrupción de los procesos puede ser pura y simple, acompañada de una advertencia o amonestación, o sujeta al cumplimiento por el sospechoso de ciertas condiciones, como el pago de los dineros, la compensación de la víctima o la libertad condicional'. 
Polít. crim. Vol. 10, № 19 (Julio 2015), Art. 1, pp. 1-24.

[http://www.politicacriminal.cl/Vol_10/n_19/Vol10N19A1.pdf]

El procedimiento monitorio penal no es más, en definitiva, que una manifestación de los necesarios cambios que acarrean el aumento de la litigiosidad en asuntos de menor relevancia y la escasez de medios materiales y personales en la Administración de Justicia que hace imprescindible la simplificación de los procesos ${ }^{34}$.

Respecto de las características del monitorio penal, siguiendo a Gimeno Sendra ${ }^{35}$, podemos destacar las siguientes:

a) Es un procedimiento especial. Se trata de un procedimiento singularmente diseñado para evitar una extensión dilatada en el tiempo ${ }^{36}$. Sin embargo, no quiere decir que sea sumario (de reducido conocimiento) sino que, al contrario, es de pleno conocimiento, solamente limitado por el hecho de la oposición del imputado o su actitud pasiva. Tan especial resulta que se podría hablar de una relación procesal retardada ${ }^{37}$. Tanto se desplaza la correcta perfección de la relación jurídico-procesal que, el monitorio penal, la difiere hasta el momento de la impugnación ${ }^{38}$.

b) Persigue ilícitos que no contemplan penas privativas de libertad ${ }^{39}$. El objeto del monitorio penal son, esencialmente, faltas que acarreen como consecuencia la pena de multa, o bien, sean substituibles otras medidas por multas. Existe, en estos casos, una condicionante muy importante y es que debe tratarse de supuestos en que concurra o bien la flagrancia del hecho, o bien la indubitada y sencilla aparición de la preexistencia del hecho punible por medios de prueba que consten en el expediente.

c) El procedimiento monitorio es esencialmente escrito. Efectivamente, pese a que la oralidad se ha ido imponiendo en nuestro sistema de justicia ${ }^{40}$, se observa una predominancia de la escritura en este procedimiento ${ }^{41}$. Esta característica, además, determina la paradoja que los procedimientos escritos reformados son más rápidos que los orales y ayudan a descongestionar el sistema de justicia.

\footnotetext{
${ }^{34}$ HINOJOSA SEGOVIA, Rafael, "Un siglo de Derecho Procesal”, Revista ICADE, No 46 (1999), pp. 147163 , p. 147.

${ }^{35}$ GIMENO SENDRA, Vicente, "Los procedimientos penales simplificados (principio de oportunidad y proceso penal monitorio)", Revista Poder Judicial, No Extra 2 (1988), pp. 3-22, pp. 10-13.

${ }^{36}$ LAPICCIRELLA, Costantino, Decreto penale di condanna, en: VV.AA., Enciclopedia del Diritto, 1962, tomo XI, p. 878: "el legislador busca ahorrar el costo de dinero, de tiempo y de personal, que el erario y las partes privadas deberían soportar por las investigaciones judiciales, cuando lo superfluo de éstas y la exactitud del pronunciamiento de condena estén demostrados por el hecho de que la condena venga aceptada por los interesados; una economía que, por consiguiente, se realiza no solamente en ventaja del Estado, sino también en ventaja de los ciudadanos".

${ }^{37}$ BELLAVISTA, Il procedimento penale monitorio, cit. nota $\mathrm{n}^{\circ} 23, \mathrm{p} .18$.

${ }^{38}$ Sería conveniente observar si se trata de una relación jurídico-procesal y si la oposición es un acto de impugnación, sin embargo el detalle excesivo escapa a los objetivos y propósitos de este trabajo.

${ }^{39}$ DOMÍGUEZ MARTÍN, El procedimiento monitorio penal, cit. nota no 27, p. 9.

${ }^{40}$ Muy interesante, en este sentido, PALOMO VÉLEZ, Diego, Reforma procesal civil, oralidad y poderes del juez, Colección Derecho y Proceso, Santiago: Ed. Legal Publishing, 2010.

${ }^{41} \mathrm{Si}$ bien es cierto que en algún caso se puede llevar a cabo en forma oral, por norma general atendida la poca gravedad de las penas, no hay control de detención, ni requerimientos orales. Un caso en que sí hubo requerimiento verbal y, finalmente, llegó a la Corte Suprema: Sentencia de 7 de enero de 2009, en causa ROL 5049-2008, Corte Suprema.
} 
DELGADO, Jordi. "Problemas y tensiones entre el diseño y funcionamiento del procedimiento monitorio penal".

d) Permite al imputado obtener una condena menor al eludir el juicio. Quizá este es el elemento principal que tiende a asegurar un mayor grado de rapidez. El silencio o falta de oposición determina la ejecutividad de la sanción penal propuesta por el ente persecutor. Ésta, además, será más beneficiosa para el imputado que, en términos teóricos, lo que pudiera obtener en un juicio oral. De este modo, se promueve la conformidad del que es imputado ocurriendo al antiguo brocardo del que calla otorga ${ }^{42}$.

Adicionalmente a las señaladas y en atención a la Recomendación 18 del Comité de Ministros del Consejo de Europa de 1987, pudiéramos también señalar, en primer lugar, que la resolución que acoge el proceso monitorio debe contar con los elementos necesarios para su acertada inteligencia. Además, debe notificarse fehaciente e indubitadamente concediendo un plazo suficiente para que el notificado pueda procurarse asesoría legal ${ }^{43}$. Por otra parte, el consentimiento que preste el notificado debe ser libre e informado y, en todo caso, su oposición pondrá fin al procedimiento monitorio ${ }^{44}$. Finalmente, es necesario enfatizar que la aceptación del procedimiento monitorio acarrea el mismo valor que una sentencia produciéndose efectos tan importantes como la autoridad de cosa juzgada y su repercusión en el non bis in idem.

Resulta, ahora, altamente interesante extraer algunas consideraciones esenciales de algunos sistemas de derecho comparado. El Derecho alemán regula en $\S 407$ a $\S 412$ del StPO el Strafberfahrens; el Derecho italiano regula el llamado "procedimento per decreto" en el art. 459 del Codice di Procedura Penale y el Derecho francés contempla en el art. 495 del Code de procédure pénale la "procédure simplifiée".

En primer lugar, debemos enfatizar que se trata de aquellas conductas penales consideradas de menor gravedad. En términos generales, pudiéramos afirmar que la multa es la pena más común para la que está diseñado este procedimiento ${ }^{45}$. Excepcionalmente se encuentra algún caso en que pudiera tratarse, también, de encarcelamiento menor a un año ${ }^{46}$. En todo caso, la justificación final es que con esta medida no se van a perjudicar los derechos de la víctima $^{47}$. De modo que, objetivamente, solo se permite perseguir las contravenciones al ordenamiento jurídico.

Subjetivamente, se dirige contra cualquier persona que ha realizado la conducta típica si bien es cierto que podemos encontrar algunos límites específicos como la minoría de

\footnotetext{
${ }^{42}$ Una relectura de este principio en DELGADO CASTRO, Jordi, "La inversión de los efectos del silencio en la reforma procesal civil: Quien calla sí otorga", Revista de Derecho de la Pontificia Universidad Católica de Valparaíso, № 42 (2014), pp. 497-522.

${ }^{43}$ De especial acierto y con una visión práctica, CASADO ROMÁN, Javier, "La notificación edictal en el juicio monitorio", Boletín del Ministerio de Justicia, Año 59, No 2003 (2005), pp. 5049-5046, p. 5049.

${ }^{44}$ DURÁN SANHUEZA, Rafael, Procedimiento simplificado y monitorio en el Código Procesal Penal chileno. Modificaciones introducidas por la Ley $N^{o}$ 20.074, Santiago: Librotecnia, 2008, p. 59.

${ }^{45} \S 407$ StPO; 495 Codice di Procedura Penale y 495 Code de procédure pénale.

$46 § 407$ StPO.

47495 Code de procédure pénale.
} 
Polít. crim. Vol. 10, № 19 (Julio 2015), Art. 1, pp. 1-24.

[http://www.politicacriminal.cl/Vol_10/n_19/Vol10N19A1.pdf]

edad $^{48}$, la reincidencia ${ }^{49}$, el carácter privativo de libertad ${ }^{50}$ de la pena, o la ausencia o imposibilidad de notificación al infractor ${ }^{51}$.

Comúnmente principia con un requerimiento por parte del Ministerio Público al Juez. ${ }^{52}$ Éste si lo encuentra fundado, no le genera dudas ${ }^{53}$, y ajustado a las causales previstas en la ley lo acoge inmediatamente notificando esta decisión al infractor ${ }^{54}$.

El requerimiento debe ser notificado al infractor en forma fehaciente y con un tiempo suficiente que no perjudique sus intereses permitiendo su adecuada defensa. Además, debe contener los datos que permitan su acertada inteligencia para no generar su indefensión ${ }^{55}$.

Una vez notificado comienza a correr un plazo en el que el sujeto pasivo puede adoptar dos actitudes. En primer lugar, puede aceptar lo solicitado por el Ministerio Público en el requerimiento, o bien, en segundo, puede oponerse a dicho requerimiento ${ }^{56}$.

Resulta muy interesante, procedimentalmente hablando, destacar que en este tipo de procedimiento se produce una eliminación del contradictorio y del procedimiento por audiencias. Efectivamente, en el procedimiento monitorio penal la relación procesal se conforma inaudita altera parte y a no ser que exista oposición no van a poder desarrollarse

\footnotetext{
48495 Code de procédure pénale.

49495 Code de procédure pénale.

50 495-1 Code de procédure pénale.

${ }^{51} \S 408$ StPO; 460.4 Codice di Procedura Penale; En el caso del 495-3 del Code de procédure pénale se permite al imputado que no fue correctamente notificado un plazo de oposición de hasta 30 días desde la fecha en que fue informado.

52 § 408 StPO; 495 Code de procédure pénale y 459 Codice di Procedura Penale.

${ }^{53}$ En caso contrario, deberá citar a una audiencia o continuar con el procedimiento aplicable (\$ 408 StPO y 495-1 Code de procédure pénale).

${ }^{54} 459$ Codice di Procedura Penale.

${ }^{55}$ El contenido del requerimiento es relativamente común y contempla menciones como los datos personales del infractor y, eventualmente de su contraparte; el nombre del defensor; la descripción de los hechos, el lugar y momento de la comisión del ilícito; las normas vulneradas; la prueba que obra en su contra; la determinación de las consecuencias jurídicas $y$, finalmente, la consecuencia de que la no oposición determinará que la sanción sea firme, ejecutoriada y produzca autoridad de cosa juzgada. En este sentido, § 409 StPO; 495-2 Code de procédure pénale, y el 460 Codice di Procedura Penale que muy en la línea de nuestro ordenamiento jurídico añade la necesidad de que el requerimiento venga fechado y firmado por el juez y la persona que autoriza su firma.

${ }_{56}$ En el caso del $§ 411$ StPO la oposición determinará la fijación de la fecha para una audiencia que no estará predeterminada por lo que se postuló en el requerimiento. El art. 495-2 del Code de procédure pénale establece un plazo de oposición de 45 días y, en caso contrario, se ejecutará lo dispuesto en el requerimiento. Por su parte, el art. 461 del Codice di Procedura Penale establece un plazo de 15 días posteriores a la notificación en las que pueden ocurrir a un recurso de casación contra el requerimiento emitido en su contra. En caso de no existir oposición o ser considerada esta extemporánea se podrá proceder a la ejecución.
} 
DELGADO, Jordi. "Problemas y tensiones entre el diseño y funcionamiento del procedimiento monitorio penal".

a cabalidad los principios del procedimiento ${ }^{57}$, en tanto que la decisión del juez se convierte en una auténtica sentencia con mérito ejecutivo ${ }^{58}$.

De este modo, se estaría atentando contra el antiquísimo brocardo latino que postula que nulla poena sine iudicio ${ }^{59}$. Sin ser un tema exento de polémica, entendemos que hoy en día se encuentra superado y que en el proceso penal se justifica por la menor importancia de las sanciones que se arriesgan.

Solamente, la oposición del imputado generará la conformación de una relación jurídico procesal completa e inspirada en un proceso contradictorio. De este modo, en todos los modelos de derecho comparado, así como en los modelos de monitorio civil, se observa una relación procesal postergada.

Haciendo acopio, entonces de todos los elementos vistos, pudiéramos aproximar una definición transversal que señale que el procedimiento monitorio penal es aquel procedimiento especial que persigue faltas o delitos menores obteniendo la generación de un título ejecutivo inmediato, siempre que el imputado no se oponga y se convierta en un procedimiento de mayor complejidad.

\section{El procedimiento penal monitorio chileno.}

El procedimiento monitorio penal llega a Chile con la Reforma Procesal Penal ${ }^{60}$. Pese a ser una institución procesal novedosa, no hubo un estudio acabado por parte de la doctrina.

En una revisión de su incorporación a nuestro ordenamiento, no es sino hasta el Segundo Informe de la Comisión de Constitución que aparece la referencia al monitorio por primera vez en la Historia de la Ley ${ }^{61}$. Se trata de un procedimiento concentrado cuya finalidad

${ }^{57}$ GANDULFO RAMÍREZ, Eduardo, "Principios del Derecho Procesal Penal en el nuevo sistema de procedimiento chileno", Revista de Derecho de la Pontificia Universidad Católica de Valparaíso, N N $^{\circ} 0$ (1999), pp. 415-474, pp. 415 y ss.

${ }^{58}$ La Ley Rituaria chilena no dejó dudas al establecer que la resolución "se tendrá, para todos los efectos legales, como sentencia ejecutoriada".

${ }^{59}$ Efectivamente, la mejor doctrina ha señalado que se trata de un tema que no genera dudas doctrinales o jurisprudenciales en la actualidad: PÉREZ RAGONE, Álvaro, "En torno al procedimiento monitorio desde el derecho procesal comparado europeo: caracterización, elementos esenciales y accidentales", Revista de Derecho, Universidad Austral de Chile, vol. 19, No 1 (2006), pp. 205-235.

${ }^{60}$ Como bien describe, CAROCCA PÉREZ, Alex, Manual el nuevo proceso penal, Tercera Edición, Santiago: Editorial LexisNexis, 2005, p. 263: "Se trata de la recepción en Chile en forma explícita de la denominada "técnica monitoria", ampliamente conocida en Europa continental y que se caracteriza porque permite el pronunciamiento de una sentencia sin un juicio controvertido previo, sino que sólo con el requerimiento del actor".

${ }^{61}$ Historia de la Ley $\mathrm{N}^{\circ} 19.696$, p. 1155. En este momento, y muy correctamente, se define como: "procedimiento monitorio, para el caso de que se trate de una falta sancionable sólo con pena de multa. En esta situación, si el imputado paga la multa, o no controvierte el requerimiento ni el monto de la multa, se entiende que la resolución del tribunal que acoge el requerimiento y ordena el pago de la multa, notificada al imputado, hace las veces de sentencia definitiva ejecutoriada. Si, por el contrario, el imputado manifiesta su disconformidad, se prosigue el procedimiento simplificado de la manera antes descrita. Cabe destacar que 
Polít. crim. Vol. 10, № 19 (Julio 2015), Art. 1, pp. 1-24.

[http://www.politicacriminal.cl/Vol_10/n_19/Vol10N19A1.pdf]

principal es agilizar el proceso penal tanto para los operadores jurídicos, como para los imputados $^{62}$.

Sin embargo, su falta de antecedentes en nuestro ordenamiento no ha permitido generar reflexiones más profundas, ni una discusión acabada sobre su arribo a nuestros tribunales de justicia. Como otras figuras ${ }^{63}$, aparecen sin mayores justificaciones en las historias que acompañan las leyes y, lamentablemente, no nos permiten conocer las razones autenticas que el legislador tiene a la vista.

En este marco, solamente se han señalado algunos motivos muy someramente: la realización de juicios rápidos en los supuestos en que se imputan faltas cuyas penas son bajas ${ }^{64}$; el permitir que el Juez de Garantía conozca y falle, en forma breve, determinados asuntos que no revisten mayor complejidad ${ }^{65}$; la necesaria legitimidad del derecho del imputado a ser juzgado dentro de un plazo razonable sin dilaciones indebidas ${ }^{66}$; la ausencia de necesidad de un juicio oral, en aquellos supuestos en que los hechos no son complejos ${ }^{67}$; la imposibilidad material de juzgar la nada desdeñable cantidad de ilícitos de bagatela ${ }^{68}$; el uso de mecanismos destinados a resolver delitos de menor entidad ${ }^{69}$; y, redundando, en la misma idea facilitar la labor de los tribunales, del Ministerio Público y actuaciones del imputado, pagando anticipadamente una multa ${ }^{70}$.

Quizá por su visión interna, son más acertados los comentarios de Salas Astrain ${ }^{71}$ quien nos hace caer en la cuenta que durante la vigencia del antiguo procedimiento la gran mayoría de faltas estaban bajo la esfera de atribuciones de los Jueces de Policía Local y su ineficaz procedimiento escrito. A su vez, la falta de interés de aquellos en la labor persecutoria conducía a un alto grado de impunidad, en especial a aquellos supuestos contemplados en los artículos 494 a 497 del Código Penal. De este modo, se profesionaliza la persecución a la vez que se genera un instrumento procesal idóneo para este tipo de supuestos.

esta institución existe en sistemas comparados, por ejemplo en el alemán, con satisfactorios resultados de descongestión del sistema".

${ }^{62}$ Historia de la Ley $\mathrm{N}^{\circ}$ 19.696, p. 1525: "La finalidad de esta norma no es solamente facilitar la labor tanto de los tribunales como del ministerio público, sino también darle la posibilidad al imputado de evitarse el juicio, pagando anticipadamente la multa".

${ }^{63}$ Un buen ejemplo de ello pudiera ser la incorporación del recurso de unificación de jurisprudencia en el ordenamiento laboral.

${ }^{64}$ CAROCCA PÉREZ, Manual el nuevo proceso penal, cit. nota n ${ }^{\circ}$ 60, p. 257.

${ }^{65}$ HERMOSILLA IRIARTE, Francisco y AGUILAR BREVIS, Alejandro, Procedimientos especiales en el nuevo proceso penal: procedimiento abreviado, procedimiento simplificado, procedimiento monitorio, procedimiento por delito de acción privada, tratamiento de la acción civil en aquellos, Santiago: Librotecnia, 2004, p. 74.

${ }^{66}$ HORVITZ LENON/ LÓPEZ MASLE, Derecho Procesal Penal chileno, t. I, cit. nota n ${ }^{\circ}$ 16, p. 460.

${ }^{67}$ HORVITZ LENON/ LÓPEZ MASLE, Derecho Procesal Penal chileno, t. I, cit. nota n ${ }^{\circ} 16$, p. 460.

${ }^{68}$ ROXIN, Claus, Derecho Procesal Penal, Buenos Aires: Editores del Puerto, 2005, p. 553.

${ }^{69}$ MATURANA MIQUEL, Cristian y MONTERO LÓPEZ, Raúl, Derecho Procesal Penal, Tomo I, Santiago: Legal Publishing, 2010, p. 1078.

${ }^{70}$ PFEFFER URQUIAGA, Emilio, Código Procesal Penal. Anotado y Concordado, Santiago: Editorial Jurídica de Chile, 2001, p. 379.

${ }^{71}$ SALAS ASTRAIN, Jaime, Problemas del proceso penal. Investigación, etapa intermedia y procedimientos especiales, Santiago: Librotecnia, 2009, p. 316. 
DELGADO, Jordi. "Problemas y tensiones entre el diseño y funcionamiento del procedimiento monitorio penal".

El esquema de tramitación tuvo un diseño muy sencillo, tal y como acontece en este tipo procedimental habitualmente. El fiscal dispone de un plazo de cinco días desde la denuncia para presentar ante el Juez de Garantía un requerimiento que, especialmente, deberá contener una propuesta sobre la multa que ha de aplicarse al imputado.

Encontramos, entonces dos requisitos fundamentales: en primer lugar, el procedimiento monitorio penal solamente ha de aplicarse a supuestos que se trate de un supuesto (falta) sancionable exclusivamente con la pena de multa ${ }^{72}$ y el fiscal debe realizar un requerimiento al Juez de Garantía ${ }^{73}$.

El Juez de Garantía, por su parte, ha de evaluar el requerimiento y, en el caso de encontrarlo fundado, lo acogerá inmediatamente mediante resolución. Ésta informará de las actitudes que puede adoptar el imputado: oponerse a lo resuelto o allanarse y las consecuencias que acarrea cada uno de estos extremos. Adicionalmente, el imputado podría no hacer nada y estaríamos en un supuesto equivalente al allanamiento ${ }^{74}$.

Poco más profundo que lo descrito han sido las consideraciones doctrinales nacionales ${ }^{75}$. Quizá, llama la atención, la ausencia de autonomía destacada por algunos autores, especificando que nos encontramos ante un procedimiento sumarísimo que constituye una derivación del procedimiento simplificado ${ }^{76}$. Esta característica está motivada por la estrecha relación que une a ambos procedimientos, en tanto que el simplificado recibirá plena aplicación en el supuesto de que el imputado se oponga al monitorio ${ }^{77}$, sin embargo, a

${ }^{72}$ HORVITZ LENON/ LÓPEZ MASLE, Derecho Procesal Penal chileno, t. I, cit. nota nº 16, p. 496.

${ }^{73}$ HORVITZ LENON/ LÓPEZ MASLE, Derecho Procesal Penal chileno, t. I, cit. nota n ${ }^{\circ}$ 16, p. 496.

${ }^{74}$ El artículo 392 CPP ha sido claro al establecer que no reclamar sobre la procedencia o monto de la sanción equivale aceptar su imposición.

${ }^{75}$ Solamente, ha habido algunas especificaciones menores que nos han ayudado a comprender mejor la figura. Como por ejemplo, CHAHUÁN SARRÁS, Sabas, Manual del Nuevo procedimiento penal, Quinta edición, Santiago: Editorial LexisNexis, 2002, p. 277: "En segundo lugar, es imperioso fijar la atención en el hecho que el criterio general que determina la aplicación de este procedimiento no está dado por una medida de claro corte objetivo, cual sería la pena abstracta prevista para el delito que se trate, sino por la pena concreta propuesta por el fiscal en cada caso, habida consideración del ilícito cometido, del grado de ejecución del delito, de la autoría o participación que se le atribuya al imputado y de la eventual concurrencia de circunstancias modificatorias de la responsabilidad".

${ }^{76}$ En este sentido, HORVITZ LENON/ LÓPEZ MASLE, Derecho Procesal Penal chileno, t. I, cit. nota ${ }^{\circ}$ 16, p. 496: "Este procedimiento especial y sumarísimo constituye una derivación del procedimiento simplificado que tiene como modelo instituciones similares del derecho comparado. Sólo resulta procedente cuando se trate de la persecución penal de faltas en las que el fiscal requiera únicamente la imposición de una pena de multa. Podría tratarse de faltas que tuvieran asignada sólo pena de multa o multa copulativa o disyuntivamente con la de prisión u otras de distinta naturaleza. En todos estos casos, el fiscal deberá señalar en su requerimiento el monto de la multa cuya imposición solicita al tribunal". Por su parte, CAROCCA PÉREZ, Manual el nuevo proceso penal, cit. nota $\mathrm{n}^{\circ}$ 60, p. 263: "Se puede definir al procedimiento monitorio, como un procedimiento que permite el pronunciamiento de una sentencia con el solo mérito de los antecedentes proporcionados en un requerimiento escrito por el fiscal, la que si es condenatoria se notifica al imputado y se le concede un plazo para oponerse; si lo hace da origen a un procedimiento oral simplificado; y, si no lo hace, la multa queda a firme y se procede a su ejecución".

77 Así, CORREA SELAMÉ, Jorge, Curso de Derecho Procesal Penal, Santiago: Ediciones Jurídicas de Santiago, 2005, pp. 275 y ss.: "Si el imputado paga dicha multa o transcurre el plazo de 15 días desde la notificación de la resolución que la impuso, sin que el imputado haya reclamado sobre su procedencia o 
Polít. crim. Vol. 10, № 19 (Julio 2015), Art. 1, pp. 1-24.

[http://www.politicacriminal.cl/Vol_10/n_19/Vol10N19A1.pdf]

la luz de su tradición histórica perfectamente podríamos señalar que se trata de categorías autónomas ${ }^{78}$.

\section{Algunos problemas que rodean la institución.}

Pese a la aparente sencillez de este procedimiento se han ido observando algunas vicisitudes que dan cuenta de que, incluso, los procedimientos más sencillos no están libres de generar aspectos controvertidos.

\subsection{La paradoja de la oralidad.}

En primer lugar, llama la atención que uno de los principales procedimientos en el proceso penal sea eminentemente escrito. Efectivamente, a pesar de que la oralidad fue la gran conquista de en la Reforma Procesal Penal, estadísticamente el procedimiento monitorio significa una carga significativa y ésta se realiza por escrito ${ }^{79}$. Al contrario, podríamos señalar que lo más excepcional es que los requerimientos se realicen en forma oral, normalmente motivado porque la menor importancia de las sanciones no amerita de disponer controles de detención, por lo tanto todo el procedimiento se lleva a cabo por escrito.

monto, se entiende que acepta su imposición. En este evento la resolución se tiene, para todos los efectos legales, como sentencia ejecutoriada. Por el contrario, si dentro del mismo plazo de 15 días el imputado manifiesta, de cualquier modo fehaciente, su falta de conformidad con la imposición de la multa o su monto, se debe proseguir con el procedimiento simplificado, al igual que cuando el juez no considera suficientemente fundado el requerimiento o la multa propuesta por el fiscal".

${ }^{78}$ NUÑEZ VÁZQUEZ, J. Cristóbal, "Los procedimientos simplificado y monitorio", en: EL MISMO, Tratado del Proceso Penal y del juicio oral, Santiago: Editorial Jurídica de las Américas, 2009, pp. 421: "El procedimiento monitorio, a diferencia del procedimiento simplificado, que tiene un carácter eminentemente sancionatorio, constituye un expediente de mero aviso, advertencia o llamado al orden emanado del juez, seguido de una sanción pecuniaria que puede o no ser impuesta, que exhorta al imputado a no incurrir en lo futuro en nuevas infracciones". En contra, podríamos citar a SILVA MONTES, Rodrigo, Manual de Procedimiento Penal, Santiago: Editorial Jurídica de Chile, 2001, p. 133: "En verdad, no es más que el procedimiento simplificado que acabamos de estudiar, con algunas modificaciones, y que se aplica cuando la pena pedida sea sólo una multa". También la jurisprudencia lo diferencia, entregando autonomía a la categoría (sentencia de 30 de septiembre de 2010, en causa ROL 119-2010, de la Corte de Apelaciones de Antofagasta): "en el Título I del Libro IV del Código Procesal Penal que se denomina "Procedimiento Simplificado" se regulan tanto el requerimiento en procedimiento monitorio, el procedimiento simplificado del art. 395 con admisión de responsabilidad y el Juicio Oral Simplificado".

${ }^{79}$ Por ejemplo, analizadas todas las causas en sede de Juzgado de Garantía del mes de enero de 2014 (fuente: www.poderjudicial.cl) observamos que se acogieron 5.343 procedimientos monitorios, a nivel país, significando casi un $11 \%$ de las 48.861 causas terminadas. Por lo tanto, pese a las diferencias según el territorio jurisdiccional podemos afirmar que el monitorio es un procedimiento con significación relevante y, en algunos casos supone más del $40 \%$ de los procedimientos terminados como en el caso del Juzgado de Garantía de Taltal o el 30\% de Toltén. Los datos mostrados por el Informe Cuatrimestral Enero-Abril 2014 de la Defensoría Penal Pública señalan un 2,8\% en el caso de los ingresos por causas monitorias y un 3,3\% en cuanto a los procedimientos por los cuales se procesó cada causa, sin embargo, estos son solo los casos en los que interviene la Defensoría. 
DELGADO, Jordi. "Problemas y tensiones entre el diseño y funcionamiento del procedimiento monitorio penal".

Así, el requerimiento del Fiscal debe ser por escrito y, habitualmente, se realiza mediante un sistema computacional que conecta la Fiscalía con el Juzgado de Garantía. A su vez, el Juez de Garantía debe revisar por sí mismo el requerimiento y si lo encuentra fundado debe acogerlo de inmediato. Esta secuencia continúa notificándose al imputado y, como vemos, todas las diligencias se realizan por escrito.

En todo caso, esta característica no genera un problema en sí mismo. Por el contrario, debe llevarnos a reflexionar acerca del necesario uso de la escrituración en aquellos momentos en que es oportuna y eficaz y no perder la razón a la hora de defender algunas actuaciones por escrito $^{80}$.

\section{2. ¿Y qué es un requerimiento fundado?}

Lamentablemente, por la importancia práctica que ello tiene, no parece haber quedado suficientemente claro qué ha de entenderse por requerimiento fundado. Efectivamente, pareciera un concepto sencillo. Ya que en el procedimiento monitorio rigen supletoriamente las normas destinadas a la regulación del procedimiento simplificado, pareciera aplicarse, entonces, el artículo 391 del Código de Procedimiento Civil (en adelante, “CPC”) y, por lo tanto, el requerimiento deberá contener la individualización del imputado, una relación sucinta del hecho que se atribuye y las circunstancias que lo permiten identificar, la cita de la disposición legal infringida, la exposición de los antecedentes o elementos que fundamentan la imputación y, finalmente, la individualización y firma del requirente. A estos requisitos, debería añadirse el monto exacto de la multa ${ }^{81}$. Por lo tanto, observamos que se debe señalar el hecho, sus circunstancias, el precepto vulnerado y el monto de la multa. Se antoja como una narración sencilla, en especial, si ha habido detención, puesto que muchos de estos datos constarán en los antecedentes policiales.

Pese a todo, esa aparente simpleza no pareciera ser tal y, en ocasiones, se rechazan los requerimientos por no encontrarse fundado. No podemos indagar acerca de las notas características generales para la determinación de lo que ha de entenderse por requerimiento fundado, puesto que la decisión judicial solamente constata el que a criterio del Juzgado de Garantía no se cumple con el requisito, pero nunca se entra a exponer los motivos ${ }^{82}$.

\footnotetext{
${ }^{80}$ Muy interesante, en este sentido, resulta observar la defensa de algunas instancias escritas en procedimientos eminentemente orales y la racionalización de los recursos que, en ocasiones esto provoca. Véase, NIEVA FENOLL, Jordi, "Los problemas de la oralidad", Revista do Ministério Público do RS, No 67, set. 2010-dez. 2010, pp. 237-257.

${ }^{81}$ La Ley $\mathrm{N}^{\circ}$ 19.762, de 13 de octubre de 2001, substituyó el inciso primero del artículo 392 CPC de modo que se exige que el Fiscal indique la cuantía exacta de la multa y no una mera propuesta como rezaba la redacción original.

${ }^{82}$ Baste como ejemplo la resolución del Juzgado de Garantía de Talca, de 20 de mayo de 2014, en causa R.U.C.: 1400461192-7 y R.I.T.: 4068-2014: "no encontrándose suficientemente fundado el requerimiento, se fija audiencia para juicio simplificado el día 27 de junio de 2014, a las 09:45 horas en este Tribunal de Garantía". Esta fórmula ha sido reiterada en nuestros tribunales y, como se observa, no permite conocer los límites o alcances de qué ha de entenderse por fundamentación en el requerimiento monitorio. El mismo Juzgado de Garantía en resolución de 13 de mayo de 2014, en causa R.U.C.: 1400007650-4 y R.I.T.: 38062014, emplea una fórmula más breve, si cabe: "No encontrándose suficientemente fundado, se resuelve"
} 
Polít. crim. Vol. 10, № 19 (Julio 2015), Art. 1, pp. 1-24.

[http://www.politicacriminal.cl/Vol_10/n_19/Vol10N19A1.pdf]

En este escenario, se produce una contradicción con el estándar general de convencimiento que genera problemas de aplicación práctica. Así, existe una compleja relación entre los antecedentes que fundan los requerimientos y del estándar de convicción exigido al juez para dar lugar a los mismos, puesto que, en general, los jueces funcionan bajo la lógica de la duda razonable y, sinceramente, no pareciera ser aplicable a este tipo de procedimiento.

Solamente, el ojo clínico ${ }^{83}$ de los Jueces de Garantía puede explicar este fenómeno ${ }^{84}$. Parece muy extraño que los requerimientos de la Fiscalía ${ }^{85}$ no contengan los requisitos que pide la ley y más difícil es comprender el que los Jueces de Garantía quieran sobrecargar su trabajo. Ahí, el mayor contrasentido ya que lo que provoca una perplejidad en este tipo de situaciones es que el Juez deberá fijar una audiencia generando más trabajo para el órgano jurisdiccional. Por otra parte, debemos poner este dato en relación con que se trata, solamente, de una multa; que, en todo caso, el requerido tiene la posibilidad de oponerse cuando considere que se están vulnerando sus derechos; y que tampoco le significa a futuro la incorporación a la categoría de irreprochable conducta anterior ${ }^{86}$. En suma, se produce

\footnotetext{
${ }^{83}$ Probablemente, se produce el fenómeno descrito por Couture como enjuiciamiento prima facie en que el juez decide en primer plano de examen si la pretensión puede ser acogida o rechazada (COUTURE, Eduardo, Fundamentos del Derecho Procesal Civil, Santiago: Editorial Metropolitana, 2010, pp. 230 y 231; Existe, un análisis pormenorizado sobre si efectivamente podemos hablar de enjuiciamiento prima facie en NIEVA FENOLL, Jordi, Enjuiciamiento prima facie, Barcelona: Atelier, 2007, pp. 125 a 128.

${ }^{84}$ En todo caso, es bien cierto que el requerimiento permite al Juez conocer todas las circunstancias que rodean al acontecimiento y en su caso, le permite evaluar la necesitad de citar a audiencia para esclarecer los hechos. Puede verse en relación, sentencia de 3 de septiembre de 2010, en causa ROL 595-2010, de la Corte de Apelaciones de Temuco: "En suma, el requerimiento contiene todos los elementos del delito a que se refiere y si el tribunal lo cuestiona, no hay en verdad admisión de responsabilidad, y debe en consecuencia haber juicio".

${ }^{85} \mathrm{Si}$ bien es cierto que como señala la sentencia de la 2 de junio de 2014, en causa ROL 748-2014, de la Corte de Apelaciones de San Miguel, a veces la Fiscalía puede ser excesivamente creativa: "el cuestionamiento del Juez se funda en que el Ministerio Público varió la calificación jurídica de los hechos, de robo con intimidación a amenaza con arma blanca, eliminando frases de la descripción de los hechos contenidos en la formalización con el objeto de hacer compatible el requerimiento con el procedimiento monitorio, omitiendo asimismo en dicho relato antecedentes de la investigación que otorgan una calificación jurídica distinta que impiden juzgar estos hechos a través del procedimiento solicitado".

${ }^{86} \mathrm{Al}$ contrario, la jurisprudencia considera insuficiente haber sido condenado en procedimiento monitorio como elemento para elegir una medida cautelar más gravosa. Así, sentencia de 31 de marzo de 2010, correspondiente al ROL 357-2010, de la Corte de Apelaciones de San Miguel: "esta Corte estima que, en razón de sus antecedentes personales los cuales demuestran su arraigo laboral y, tomando en consideración que sólo registra un procedimiento monitorio con anterioridad a los hechos materia de la formalización en esta causa, otras medidas cautelares del artículo 155 del Código Procesal Penal, resultan igualmente efectivas a fin de asegurar los fines del procedimiento" (el destacado es nuestro). En el mismo sentido resulta interesante, sentencia de 11 de febrero de 2011, en causa ROL 9-2011, de la Corte de Apelaciones de Talca: "La Segunda Sala del Tribunal Oral en lo Penal de Talca, resuelve desestimar la solicitud de la defensa de XXXX en orden a que se le reconozca la atenuante de irreprochable conducta anterior, precisamente porque en copia de sentencia dictada en causa RIT 7430-2008, sobre procedimiento monitorio consta una condena en su contra por la falta del artículo 50 de la ley 20.000 en su contra, la cual se encuentra ejecutoriada según da cuenta el certificado respectivo, razón por la cual se desestima que su conducta previa a los hechos esté exenta de macula". Añade esta misma: "En efecto, al parecer no cualquier anota noción penal tiene la idoneidad necesaria para lograr, configurar una reprochabilidad de tal magnitud que impida considerar a favor del agente la aminorante en comento, así, las condenas por faltas no pueden ni deben legalmente considerarse para tal fin, conclusión a la que se arriba a partir de la interpretación de los numerales 15 y 16
} 
DELGADO, Jordi. "Problemas y tensiones entre el diseño y funcionamiento del procedimiento monitorio penal".

una situación ininteligible, ya que un mecanismo de descongestión termina generando nuevas audiencias sin que se puedan vislumbrar claramente los beneficios de las mismas ${ }^{87}$.

Además, se produce la lamentable circunstancia que prácticamente queda a un criterio discrecional y no controlable por los Tribunales Superiores ${ }^{88}$. Así, el argumento que han ido entregando las Cortes de Apelaciones para evitar entrar a conocer de recursos de apelación contra rechazos a los requerimientos en procedimientos monitorios es que no entran dentro de las categorías recogidas por el artículo 370 del Código Procesal Penal (en adelante, "CPP"). En especial, pese a reconocerse habitualmente que se provoca el término del procedimiento y, que por lo tanto el Ministerio Fiscal está recurriendo amparado en una de las causales, se interpreta que el juicio simplificado consecuencial es la forma en que se le da curso al procedimiento y, de este modo, no se cumple a cabalidad con lo dispuesto en las causales para el recurso de apelación ${ }^{89}$.

Sin duda, es también un tema que huelga decir que no resulta sencillo. Por una parte, los requerimientos tienen los datos que permiten al Juez de Garantía tomar una decisión sobre el mismo, como contrapeso a que el Ministerio Fiscal tenga facultades cuasi jurisdiccionales inmediatas y no siempre sea automática su propuesta de sanción ${ }^{90}$. Por otra

del art. 12, en relación con el art. 104, del Código Penal desde que, si por una parte las faltas no pueden considerarse ni para las reincidencias de carácter general ni para las especiales, por expreso mandato, en armonía con ello, parece del toro improcedente impedir la consolidación de la atenuante que nos ocupa en merito a una anota noción de la misma envergadura".

${ }^{87}$ Solo el debido proceso y la presunción de inocencia permiten que esto suceda. Que se promueva una investigación más acuciosa y se dé voz al imputado. Pareciera que uno de los argumentos que ha encontrado la jurisprudencia menor es la falta de correspondencia con los principios generales del proceso penal. Por ejemplo, Corte de Apelaciones de Talca, de 16 de noviembre de 2007: "Que los fundamentos que preceden no se condicen con lo estatuido por el artículo 392 del Código Procesal Penal, pues el juez invalida su aplicación, cuestionando la constitucionalidad de dicho precepto legal. Debe tenerse en cuenta que el mismo artículo garantiza el derecho a la defensa del imputado y, en especial, el derecho a reclamar, pudiendo el mismo juez, a mayor abundamiento, al instruir al imputado conforme el texto lo ordena, dotarlo de abogado defensor".

${ }^{88}$ Solamente si indirectamente llega a conocimiento del superior jerárquico podría ser controlado mediante la declaración de nulidad, como pasa en el citado caso de la Corte de Apelaciones de Talca, de 16 de noviembre de 2007: "la decisión del juez de garantía ocasiona un evidente perjuicio al Ministerio Público, pues le veda la posibilidad de emplear un procedimiento consagrado en la ley, cual es, el monitorio, lo que resulta reparable sólo con la declaración de nulidad del acto viciado, estando este tribunal ad quem facultado para hacerlo de oficio, con arreglo a las normas de los artículos 159, 160 y 163 del Código Procesal Penal".

${ }^{89}$ Un ejemplo de ello, puede observarse en la resolución de la Corte de Apelaciones de Talca, de 16 de noviembre de 2007: "Que la resolución motivo del recurso, no es susceptible de apelación, toda vez que no se enmarca en ninguna de aquellas indicadas en el artículo 370 del Código Procesal Penal. Aunque impide la realización del procedimiento monitorio, ordena la continuación a través del simplificado, de forma tal que no se ha producido el término, no se ha impedido la prosecución, ni se ha decretado la paralización por más de treinta días, del procedimiento en el que debe recaer el pronunciamiento judicial, de fondo; tampoco existe una norma específica que la haga apelable".

${ }^{90}$ Diáfana resulta la sentencia de la 2 de junio de 2014, en causa ROL 748-2014, de la Corte de Apelaciones de San Miguel: "el Juez en el procedimiento simplificado tiene la facultad de efectuar un examen respecto a la suficiencia de los antecedentes aportados por el Ministerio Público para admitir a trámite el requerimiento, facultad que también se encuentra presente en el artículo 392 respecto del requerimiento en procedimiento monitorio, a cuyo respecto, el juez está facultado para aceptarlo inmediatamente dictando la 
Polít. crim. Vol. 10, № 19 (Julio 2015), Art. 1, pp. 1-24.

[http://www.politicacriminal.cl/Vol_10/n_19/Vol10N19A1.pdf]

parte, basta con una negativa simple para que esa decisión se siga por procedimiento simplificado y el Ministerio Público quede sin comprender cuales fueron los verdaderos motivos.

Si bien es cierto que algún caso específico generó debate acerca de la posibilidad de impetrar recurso de apelación. En concreto, el supuesto al que nos referimos es aquel en que el Juez de Garantía ordena la complementación o aclaración de algún extremo del requerimiento. Este fenómeno no está contemplado en el CPP y, por lo tanto, algunos Fiscales entendían que se estaba entorpeciendo la acción penal impidiendo la prosecución del juicio ${ }^{91}$. La verdad es que la casuística entrega soluciones diversas, aunque existiendo un requisito no contemplado por la ley que genera una carga extraordinaria de trabajo y que, inevitablemente, produce el efecto de hacer imposible la prosecución del procedimiento en el caso de incumplimiento, parece más que razonable que se conceda el recurso de apelación amparado en lo establecido por el artículo $370 \mathrm{CPC}^{92}$.

En este punto, empero, merece la pena sostener que la idea primigenia del procedimiento monitorio es la obtención de un título ejecutivo en forma inmediata y, por lo tanto, aquellas decisiones judiciales que, de una forma u otra, impiden el logro de este objetivo están desnaturalizando la institución $\mathrm{y}$, de paso, generando un desequilibrio entre los intervinientes al reconvertir el procedimiento en una especie más garantista. Este tipo de causas menores, no ameritan una inversión de recursos personales y materiales más elevada, y sería bueno que mediante el recurso de apelación se pudiera controlar esa tentación de algunos jueces de entregar mayores garantías o bien, confirmar que el

resolución pertinente. Y por el contrario, si el juez no considerare suficientemente fundado el requerimiento o la multa propuesta por el fiscal, no aceptará la sustitución del procedimiento"

${ }_{91}$ Ejemplo de esta alegación por parte de la Fiscalía en sentencia de 31 de mayo de 2011, correspondiente al ROL 1086-2011, de la Corte de Apelaciones de Santiago.

${ }^{92}$ En este mismo sentido lo entendió la propia Corte de Apelaciones de Santiago en que se ordenó al Ministerio Público transcribir en su integridad la declaración de un testigo, bajo apercibimiento de no tenerse por presentado el mismo (sentencia de 7 de junio de 2011, correspondiente al ROL 1085-2011): " se impone una carga al ente persecutor y, además, un apercibimiento que hacen imposible la prosecución del procedimiento en la forma dispuesta por la ley, más aun si, de hacerse efectivo, deberá tenerse por no presentado el requerimiento formulado, se debe concluir que es susceptible de ser impugnada por la vía de la apelación; razón por la que el presente recurso debe ser acogido". En parecidos términos se dictó la sentencia de 7 de junio de 2011, en causa ROL 1084-2011, de la Corte de Apelaciones de Santiago. Sin embargo, la misma Corte unos días antes, resolvía un caso muy parecido con signo totalmente contrario. Efectivamente, en la sentencia de 31 de mayo de 2011, en causa ROL 1073-2011, de la Corte de Apelaciones de Santiago, se debatía, a propósito de un recurso de hecho, acerca de si la solicitud de un Juez de Garantía de completar el requerimiento agregando la declaración de la víctima constituía o no un entorpecimiento que generaba la imposibilidad de la prosecución del procedimiento. De modo que ante un supuesto, esencialmente igual, la Corte resolvió "que la resolución apelada no es de aquellas contenidas en el citado artículo 370 del Código Procesal Penal, por cuanto lo que busca es que mediante lo solicitado, se tenga mayores y mejores herramientas a fin de resolver el requerimiento de procedimiento monitorio, más si el artículo 392 del Código Procesal Penal señala en su inciso segundo que el juez debe, a fin de acoger dicho requerimiento, estimarlo suficientemente fundado, por lo que se rechaza el recurso de hecho interpuesto a fojas I". En prácticamente idénticos términos, sentencia de 31 de mayo de 2011, en causa ROL 1071-2011, de la Corte de Apelaciones de Santiago. 
DELGADO, Jordi. "Problemas y tensiones entre el diseño y funcionamiento del procedimiento monitorio penal".

Ministerio Público adoleció de una falta de rigor en la presentación del requerimiento. En el modo como se soluciona hoy, por otra parte, no nadie está equivocado.

Más sencillo pareciera poder afirmar que bajo ningún supuesto procede recurso de nulidad. Básicamente, porque si el requerido se opone, el procedimiento mutará a procedimiento simplificado y no será necesario ningún tipo de recurso, al menos hasta la decisión que resulte en ese nuevo procedimiento. Quien se pudiera sentir agraviado sería el Ministerio Público si se rechaza el requerimiento. Sin embargo, solo podría darse el escenario de que el agravio proviniera del rechazo del requerimiento, ya que el Juez de Garantía no está habilitado para ejercer modificaciones en el mismo. Entonces, el Ministerio Público no podrá sostener su pretensión de reforma en un recurso de nulidad puesto que no estaríamos ante el supuesto de invalidar ni el juicio oral, ni la sentencia definitiva.

Fácilmente, podría llegarse a una confusión. Tanto la doctrina ${ }^{93}$, como la jurisprudencia ${ }^{94}$, han señalado sin reflexionar profusamente que el recurso de nulidad es procedente en tanto que el procedimiento monitorio se conforma como especie del procedimiento simplificado y, por lo tanto, le es enteramente aplicable la norma contenida en el artículo 399 que reconoce la posibilidad de impetrar recurso de nulidad contra la sentencia definitiva. Pero una lectura cautelosa y, en especial, un reconocimiento a la autonomía de la categoría de procedimiento monitorio nos conduce ineludiblemente a señalar que no existe recurso de nulidad. En el escenario en que nos pongamos no existe causal y menos si tenemos en cuenta que la única vía a reconocer la resolución como sentencia en el artículo 392 CPP, lo hace expresando su calidad de ejecutoriada ${ }^{95}$.

\subsection{El requerimiento monitorio y la interrupción de la prescripción.}

Otro de los aspectos problemáticos en la vida forense del procedimiento monitorio penal ha sido discernir si el requerimiento interrumpe o no la prescripción de la acción penal tal y como sucede con la formalización. La norma contenida en el artículo 233 CPC no deja dudas acerca de que la formalización genera este efecto. Y, desde una aproximación superficial, pudiera parecer que el requerimiento cumple un objetivo similar y, por lo tanto,

\footnotetext{
${ }^{93}$ HORVITZ LENON/LÓPEZ MASLE, Derecho Procesal Penal chileno, cit. nota n’ 16, p. 494: "El artículo 399 CPP dispone que "contra la sentencia definitiva sólo podrá interponerse el recurso de nulidad previsto en el Título IV del Libro Tercero” del Código. Aunque no lo diga expresamente deben entenderse incluidas tanto la sentencias dictadas en el procedimiento simplificado como en el monitorio, que es solo una posible derivación del mismo". Pareciendo reconocer recurso de nulidad en el caso del procedimiento monitorio.

${ }^{94}$ Sentencia de 30 de septiembre de 2010, en causa ROL 119-2010, de la Corte de Apelaciones de Antofagasta: "En efecto, y como lo sostiene el juez recurrido, de dicha disposición se desprende que el recurso de nulidad es procedente en las tres variantes del procedimiento simplificado, a saber, procedimiento monitorio, simplificado con admisión de responsabilidad y juicio oral simplificado".

${ }^{95}$ Debemos recordar que las sentencias ejecutoriadas o firmes se caracterizan por no poder ser impugnadas y, solamente, pudiera proceder en su caso el llamado recurso de revisión (MOSQUERA RUIZ, Mario y MATURANA MIQUEL, Cristián, Los recursos procesales, Santiago: Editorial Jurídica de Chile, Santiago, 2010).
} 
Polít. crim. Vol. 10, № 19 (Julio 2015), Art. 1, pp. 1-24.

[http://www.politicacriminal.cl/Vol_10/n_19/Vol10N19A1.pdf]

debería poder generar idénticos efectos. Pero lo cierto es que uno y otro precepto no guardan relación y no son jurídicamente el mismo acto ${ }^{96}$.

La jurisprudencia ha entendido que el requerimiento debe interrumpir la prescripción del término en la acción penal, atendido que este, en cierto modo, estamos ante un acto equivalente a la comunicación que produce la formalización ${ }^{97}$. Pero además, la propia Corte Suprema ha señalado que la entrada en vigor del Código Procesal Penal, no significa una modificación de las normas sustantivas penales y, por este motivo, señala que el artículo 96 del Código Penal ha de interpretarse observando el momento en que se inicia el procedimiento contra el hechor, circunstancia que puede ser pretérita a la formalización ${ }^{98}$. A su vez, la Corte de Apelaciones de Arica, acertadamente, decretó que no podría entregarse la suspensión o la interrupción exclusivamente a un acto sustancial como la audiencia de formalización ya que de lo contrario si el investigado no comparece va a ir impidiendo la suspensión ${ }^{99}$.

\subsection{La notificación en el procedimiento monitorio.}

Pero incluso cuestiones tan básicas como la notificación han generado alguna duda cotidiana. Una de las características de las que depende el éxito de cualquier procedimiento monitorio es que, imprescindiblemente, la notificación de la resolución del tribunal se haga por cualquier medio fehaciente.

Por su propia técnica, el procedimiento monitorio tiene una lógica en la que si bien se permite la defensa del deudor, no es menos cierto que imprime una velocidad procedimental que, además de desconocida en nuestro ordenamiento, puede ser fuente material de injusticia si no se toman los recaudos oportunos.

El CPP no contiene normas especiales acerca de la notificación de modo que han de aplicarse supletoriamente las normas contenidas en el CPC. En este caso, siendo la primera

\footnotetext{
${ }^{96}$ De este modo lo señala la Corte de Apelaciones de Temuco en sentencia de 26 de enero de 2011, en causa ROL 47-2011 en que ante un recurso de apelación señaló que si bien la formalización suspende la prescripción de la acción penal, a tenor de lo dispuesto en el artículo 233 letra a) CPC, "no así respecto del procedimiento simplificado, ni el procedimiento monitorio". Matizando, eso sí, que "el artículo 96 del Código Penal, ordena que se suspende la prescripción desde que el procedimiento se dirige en contra del imputado, exigencia que sobradamente cumplió el requerimiento presentado por el imputado ante el Ministerio Público de fecha siete de enero de 2010".

${ }^{97}$ En este sentido, la sentencia de 5 de marzo de 2010, correspondiente al ROL 39-2010, de la Corte de Apelaciones de Copiapó: "no puede sino convenirse con el apelante que la presentación del requerimiento para un juicio monitorio no es sino la manifestación del órgano de persecución penal de dirigir el procedimiento en contra de una persona determinada y, por lo mismo, suspende el término de prescripción de la acción penal".

${ }^{98}$ Sentencia de 17 de noviembre de 2010, en causa ROL 6139-2010, de la Corte Suprema: "no se produce (la suspensión de la prescripción de la acción) únicamente con la formalización de la investigación, pues en la especie, a lo menos, ocurre desde que el Ministerio Público presentó requerimiento contra el imputado". En este mismo sentido, sentencia de 19 de febrero de 2003, en causa ROL 5362-2003; de 13 de junio de 2006, en causa ROL 2693-2006 y de 16 de diciembre de 2008, 6268-2008, todas de la Corte Suprema.

${ }^{99}$ Sentencia de 17 de diciembre de 2010, en causa ROL 259-2010, Corte de Apelaciones de Arica.
} 
DELGADO, Jordi. "Problemas y tensiones entre el diseño y funcionamiento del procedimiento monitorio penal".

(y quizá única) resolución judicial el artículo 40 CPC indica que debe realizarse personalmente. Además, la lógica y el otorgamiento de un principio de debida defensa coinciden con esta norma y pareciera que no procede de ninguna otra forma ${ }^{100}$. Solamente, la notificación de un modo fehaciente ${ }^{101}$ permitirá que el imputado pueda, si lo considera oportuno, defenderse. De lo contrario, si la notificación no fuera personal y se consintiera otro modo, podríamos generar una condena sin audiencia.

Por lo tanto, resulta ser claro en que no se admitirá ninguna otra forma de notificación. Pudiera, eso sí, existir la salvedad de que a tenor de una audiencia, por ejemplo de control de detención, se notificara oralmente en el acto la resolución que admite el requerimiento monitorio. Pero como norma general, otro tipo de formas de notificación no se pueden dar ya que impedirían el cabal conocimiento del requerimiento, en especial intentar una notificación por el estado diario adolecería del déficit de no poder comunicar las instrucciones respecto a las posibles actitudes del imputado, ni de las indicaciones esenciales del requerimiento contenidas en las letras a), b) y c) ${ }^{102}$.

\section{Influencias en los sistemas reformados: a modo de conclusión.}

El procedimiento monitorio penal introdujo en Chile una nueva forma de concebir la litigación y la descompresión de la carga de trabajo de los tribunales. Más allá de los aspectos problemáticos concretos se comienza a instaurar un procedimiento que contrariamente a la tendencia moderna se caracteriza por su alto grado de escrituración.

Sin embargo, se consolidan ideas que determinan una forma de diseñar los procedimientos en los demás órdenes. En primer lugar, se empieza a sentir que no se genera un problema relevante si se castiga al demandado rebelde que con su actitud solamente genera costos y entorpecimientos.

Por otra parte, podemos describir un fenómeno quizá impensado. Hablamos de la inversión del contradictorio o de la ausencia de posibilidad de defensa antes de una resolución judicial que acoge lo solicitado por el Ministerio Público.

Sin duda, estas directrices van a tener gran importancia en las sucesivas reformas procesales. Efectivamente, tanto en el ámbito del procedimiento laboral, como en el

\footnotetext{
${ }^{100}$ La doctrina extranjera también coincide al señalar, por ejemplo: "La demanda se notificará de forma tal que permita que el demandado tenga suficiente para preparar su defensa. Normalmente, no son admisibles formas de notificación fingidas, porque vulneran el derecho a ser oído, el que tiene protección constitucional" (STÜRNER, Rolf, Introducción a la Justicia Civil Alemana. Principios y desarrollo del proceso de conocimiento, en: PÉREZ RAGONE, Álvaro y TAVOLARI GOYCOOLEA, Pía (Coords.) Derecho Procesal Civil Comparado, Homenaje a Rolf Stürner, Santiago: Legal Publishing Thompson Reuters, 2013, p. 17).

${ }^{101}$ De hecho para Maturana y Montero (MATURANA MIQUEL/ MONTERO LÓPEZ, Derecho Procesal Penal, Tomo I, cit. nota $\mathrm{n}^{\circ} 69$, p. 404) constituye, la notificación personal, la fórmula más perfecta y siempre procede en el supuesto que nos encontremos con la primera de las notificaciones.

${ }^{102}$ Puede consultarse un supuesto en que se trató de notificar por estado diario: Sentencia de 20 de mayo de 2011, en causa ROL 89-2011, Corte de Apelaciones de Valdivia.
} 
Polít. crim. Vol. 10, № 19 (Julio 2015), Art. 1, pp. 1-24.

[http://www.politicacriminal.cl/Vol_10/n_19/Vol10N19A1.pdf]

Proyecto de Código Procesal Civil se adoptan sendos procedimientos monitorios que no hacen sino otra cosa que consolidar esta técnica en nuestro ordenamiento y, por otra parte, integrarse en los modelos de derecho comparado continental en que este tipo de procedimientos se encuentran totalmente insertos.

Principalmente, podemos señalar que las sucesivas reformas van a seguir la línea comenzada por el monitorio penal y se van a caracterizar por incorporar procedimientos escritos en que se accede inmediatamente, por parte del tribunal, a la petición de la parte solicitante, entregando la posibilidad de que el demandado pueda oponerse cuando tenga motivos suficientes para ello.

El procedimiento monitorio ha resultado un auténtico éxito en nuestro entorno jurídico cultural y Chile moderniza sus procedimientos incorporando un clásico cuya raíz medieval no hace sino confirmar que habitualmente es mejor legislar observando la historia. 
DELGADO, Jordi. "Problemas y tensiones entre el diseño y funcionamiento del procedimiento monitorio penal".

\section{BIBLIOGRAFÍA}

ARMENTA DEU, María Teresa, Criminalidad de bagatela y principio de oportunidad: Alemania y España, Barcelona: Ed. PPU, 1991.

BELLAVISTA, Girolamo, Il procedimento penale monitorio, Milán: Giuffrè, 1952.

CALAMANDREI, Piero, El proceso monitorio, Trad. SENTÍS MELENDO, Santiago, Buenos Aires: Bibliográfica Argentina, 1946.

CALAZA LÓPEZ, Sonia, “¿Podría instaurarse una Jurisdicción Voluntaria Penal?”, Revista de Derecho UNED, № 10 (2012), pp.69-89.

CARNELUTTI, Francesco, Instituciones del Proceso Civil, Trad. SENTÍS MELENDO, Santiago, Buenos Aires: Ediciones Jurídicas Europa-América, 1973.

CAROCCA PÉREZ, Alex, Manual el nuevo proceso penal, Tercera Edición, Santiago: Editorial LexisNexis, 2005.

CASADO ROMÁN, Javier, "La notificación edictal en el juicio monitorio", Boletín del Ministerio de Justicia, Año 59, № 2003 (2005), pp. 5049-5046.

CERDA SAN MARTÍN, Rodrigo, Elementos fundamentales de la actividad probatoria, Santiago: Librotecnia, 2010.

CHAHUÁN SARRÁS, Sabas, Manual del Nuevo procedimiento penal, Quinta edición, Santiago: Editorial LexisNexis, 2002.

COLOMBO CAMPBELL, Juan, Los Actos Procesales, Santiago: Editorial Jurídica de Chile, 1997.

CORDERO, Franco, Procedura penale, Milán: Giuffrè, 2006.

CORREA DELCASSO, Juan, El proceso monitorio; Barcelona: Editorial J. M. Bosch, 1998.

CORREA SELAMÉ, Jorge, Curso de Derecho Procesal Penal, Santiago: Ediciones Jurídicas de Santiago, 2005.

COUTURE, Eduardo, Fundamentos del Derecho Procesal Civil, Santiago: Editorial Metropolitana, 2010.

CRISTOFOLINI, Giovanni, Processo d'ingiunzione, Padova: Ed. Cedam, 1939.

DELGADO CASTRO, Jordi, "La inversión de los efectos del silencio en la reforma procesal civil: Quien calla sí otorga", Revista de Derecho de la Pontificia Universidad Católica de Valparaíso, No 42 (2014), pp. 497-522.

DELMAS-MARTY, Mireille, Procesos Penales en Europa. Alemania, Inglaterra y Gales, Bélgica, Francia e Italia, Trad. MORENILLA ALARD, Zaragoza: Ed. EDIJUS, 2000.

DOMÍNGUEZ MARTÍN, Salvador, El procedimiento monitorio penal, Madrid: Instituto Nacional de Prospectiva, 1980.

DURÁN SANHUEZA, Rafael, Procedimiento simplificado y monitorio en el Código Procesal Penal chileno. Modificaciones introducidas por la Ley $N^{\circ}$ 20.074, Santiago: Librotecnia, 2008.

FAIRÉN GUILLÉN, Victor, El juicio ordinario y los plenarios rápidos, Barcelona: Bosch, 1953.

FLORIAN, Eugene, Elementos de Derecho Procesal Penal, Trad. PRIETO CASTRO, México: Editorial Jurídica Universitaria, 2002. 
Polít. crim. Vol. 10, № 19 (Julio 2015), Art. 1, pp. 1-24.

[http://www.politicacriminal.cl/Vol_10/n_19/Vol10N19A1.pdf]

GANDULFO RAMÍREZ, Eduardo, "Principios del Derecho Procesal Penal en el nuevo sistema de procedimiento chileno", Revista de Derecho de la Pontificia Universidad Católica de Valparaíso, № 20 (1999), pp. 415-474.

GIMENO SENDRA, Vicente, "Los procedimientos penales simplificados (principio de oportunidad y proceso penal monitorio)", Revista Poder Judicial, Nº Extra 2 (1988), pp. 3-22.

GUTIÉRREZ-ALVIZ Y CONRADI, Faustino, El procedimiento monitorio. Estudio de Derecho comparado, Sevilla: Anales de la Universidad Hispalense, 1978.

HERMOSILLA IRIARTE, Francisco y AGUILAR BREVIS, Alejandro, Procedimientos especiales en el nuevo proceso penal: procedimiento abreviado, procedimiento simplificado, procedimiento monitorio, procedimiento por delito de acción privada, tratamiento de la acción civil en aquellos, Santiago: Librotecnia, 2004.

HINOJOSA SEGOVIA, Rafael, "Un siglo de Derecho Procesal", Revista ICADE, No 46 (1999), pp. 147-163.

HORVITZ LENON, María Inés y LÓPEZ MASLE, Julián, Derecho Procesal Penal chileno, t. I, Santiago: Editorial Jurídica de Chile, 2008.

LAPICCIRELLA, Costantino, Decreto penale di condanna, en: VV.AA., Enciclopedia del Diritto, 1962, tomo XI.

LAUDAN, Larry, Verdad, error y proceso penal, Trad. VÁZQUEZ, Carmen; AGUILERA, Edgar, Madrid: Marcial Pons, 2013.

LONGHI, Silvio, Il Decreto Penale e le sue transformazioni, Milán: Scuola Positiva, 1911.

LORCA NAVARRETE, Antonio María, El procedimiento monitorio civil, San Sebastián: Instituto Vasco de Derecho Procesal, 1988.

MARTÍN DELPONT, José Luis, El principio de oportunidad: Análisis de Derecho Comparado, Sevilla: Anales de la Facultad de Derecho, No 28, 2011.

MATURANA MIQUEL, Cristian y MONTERO LÓPEZ, Raúl, Derecho Procesal Penal, Tomo I, Santiago: Legal Publishing, 2010.

MIRA ROS, Corazón, Régimen actual de la conformidad, Madrid: Colex, 1998.

MONTERO AROCA, Juan, El Proceso Civil. Los Procesos Ordinarios de Declaración y de Ejecución, Valencia: Tirant lo Blanch, 2014.

MOSQUERA RUIZ, Mario y MATURANA MIQUEL, Cristián, Los recursos procesales, Santiago: Editorial Jurídica de Chile, Santiago, 2010.

NIEVA FENOLL, Jordi, "Aproximación al origen del procedimiento monitorio", en: NIEVA FENOLL, Jordi; RIVERA MORALES, Rodrigo; COLMENARES URIBE, Carlos y CORREA DELCASSO, Juan Pablo, El procedimiento monitorio en América Latina, Bogotá: Temis, 2013.

, "Los problemas de la oralidad", Revista do Ministério Público do RS, N 67, set. 2010-dez. 2010, pp. 237-257.

, Jordi, Enjuiciamiento prima facie, Barcelona: Atelier, 2007.

NUÑEZ VÁZQUEZ, J. Cristóbal, "Los procedimientos simplificado y monitorio", en: EL MISMO, Tratado del Proceso Penal y del juicio oral, Santiago: Editorial Jurídica de las Américas, 2009.

PALOMO VÉLEZ, Diego, "Reformas de la ejecución civil y del proceso monitorio: La apuesta chilena por la tutela judicial efectiva y el derecho de acceso a un debido proceso", Estudios Constitucionales, Año 12, № 1 (2014), pp.475-500. 
DELGADO, Jordi. "Problemas y tensiones entre el diseño y funcionamiento del procedimiento monitorio penal".

Reforma procesal civil, oralidad y poderes del juez, Colección Derecho y Proceso, Santiago: Editorial Legal Publishing, 2010.

PÉREZ RAGONE, Álvaro, "En torno al procedimiento monitorio desde el derecho procesal comparado europeo: caracterización, elementos esenciales y accidentales", Revista de Derecho, Universidad Austral de Chile, vol. 19, № 1 (2006), pp. 205-235.

PFEFFER URQUIAGA, Emilio, Código Procesal Penal. Anotado y Concordado, Santiago: Editorial Jurídica de Chile, 2001.

PICÓ I JUNOY, Joan, "Nuevas perspectivas sobre la debida armonización del proceso monitorio y el posterior juicio ordinario", Justicia: Revista de Derecho Procesal, № 1 (2013), pp. 41-106

RAMOS GONZÁLEZ, José María, "Repercusiones penales del proceso monitorio", Poder Judicial, No 699 (1966), pp. 3-5.

ROXIN, Claus, Derecho Procesal Penal, Buenos Aires: Editores del Puerto, 2005.

SILVA MONTES, Rodrigo, Manual de Procedimiento Penal, Santiago: Editorial Jurídica de Chile, 2001.

SKEDL, Arthur, Das Mahnverfahren, Leipzig, 1891.

SPANGHER, Giorgio, Procedimenti speciali, guidizio, procedimento davanti al tribunale e in composizione monorgratica, Milán: Wolters Kluwer Italia, 2008.

STÜRNER, Rolf, Introducción a la Justicia Civil Alemana. Principios y desarrollo del proceso de conocimiento, en: PÉREZ RAGONE, Álvaro y TAVOLARI GOYCOOLEA, Pía (Coords.), Derecho Procesal Civil Comparado, Homenaje a Rolf Stürner, Santiago: Legal Publishing Thompson Reuters, 2013

TOMÁS Y VALIENTE, Francisco, "Estudio históricojurídico del proceso monitorio", Revista de Derecho Procesal, No 1 (1960), pp. 31-132.

ZAPATA GARCÍA, María Francisca, "La confesión en el nuevo sistema procesal penal: ¿Una reina que perdió su trono?”, Gaceta Jurídica, No 252 (2001), pp. 18-19. 